\title{
Developments in Dynamics of Composite Material Shafts
}

\author{
S. P. SINGH ${ }^{\mathrm{a}}$, H. B. H. GUBRAN ${ }^{\mathrm{b}}$ and K. GUPTA ${ }^{\mathrm{b}, *}$ \\ ${ }^{a}$ Department of Machine Design \& Automation Engg., Dr. B. R. A. Regional Engineering College, Jalandhar, India.; ${ }^{\mathrm{b}}$ Department of \\ Mech. Engg., Indian Institute of Technology, Delhi, India
}

(Received 17 May 1996; In final form 7 ?? 1996)

\begin{abstract}
The review traces the development of composite shafts in varied applications. The different theoretical and experimental aspects of dynamics of composite shafts, under investigation for the past two decades, are reviewed and the state of the art discussed including possible future developments.
\end{abstract}

Keywords: Composite shaft, dynamics, driveshaft design, non-metallic rotors

\section{INTRODUCTION}

Present day rotors have predominantly metallic shafts. Use of fiber reinforced composites has been attempted in a few specific applications. Studies on composite shafts started in 1970's. The most important development of composite shafts has taken place in aerospace (helicopter) industry [Kraus and Darlow, 1987 and Bielefield, 1994], and automotive applications [Kliger and Yates, 1980, Golding, 1982 and Hoffmann et al., 1994]. Other applications include the use of composite shafts as quill shaft by Spencer [1989], an aircraft power take off shaft by Garguilo [1986], generator shaft by Raghava and Hammond [1984], shaft for a cooling tower by Berg [1989], a papermill by Cox [1994] and naval propulsion systems by Wilhelmi et al. [1986]. The two U.S. patents by Worgan and Smith [1978] and Yates and Rezin [1979] indicate that the preliminary hurdles to a composite driveshaft design were overcome. Fromknecht [1992] highlighted the possible benefits accruing from the use of composite shafting in mechanical power transmission.

In the early developments, composite shafts were designed to operate in the sub-critical range. Therefore, initial studies were directed towards design requirements and in overcoming the problems in practical application. Subsequently, in order to derive greater advantage in terms of reduction of weight, the possibility of super-critical operations of composite shafts was explored. Thus, the present trend in research, as highlighted by Gupta and Singh [1996], emphasizes such aspects as rotordynamic analysis, elaborate optimization procedures, cost sensitivity analyses, and possibility of supercritical operation.

*Corresponding author. Department of Mechanical Engineering, Indian Institute of Technology, Hauz Khas, New Delhi, India 110016. Tel.: 91-11-666979, Ext. 3116. Fax: 91-11-6862037. E-mail: kgupta@mech.iitd.ernet.in. 
The work on dynamics of composite shafts is divided into three categories.

(i) Design, and Optimization

(ii) Damage Tolerance Studies

(iii) Rotordynamic Studies

\section{DESIGN ASPECTS}

The design aspects for composite shafts vary from one application to another. Kliger and Yates [1980] discussed the design and material considerations for composite driveshafts in automotive applications. Initially, the materials used for the driveshafts were glass/epoxy and boron/epoxy. However, as developments in composite technology continued, carbon fibers became more readily available. In many of the current applications they replaced boron fibers, which had proved too costly and were difficult to process. In automotive driveshafts, carbon fibers were found to be particularly suitable. Hybridization with glass/epoxy was also tried, and proved cost effective as shown by Linsenmann [1978].

Belingardi et al. [1990] showed that carbon fiber becomes a necessity when a critical balance between torque, diameter, length and natural frequency cannot be achieved with metallic or glass/epoxy configurations. The stepwise description of the complete design procedure which is adopted for replacement of a two piece metallic automotive driveshaft by a single piece composite shaft was described by Spencer and McGee [1985]. The optimization objectives and the payoffs obtained were also discussed.

One of the problems associated with design of composite driveshafts has been the accurate determination of the flexural critical speeds. As the driveshafts are quite long, their critical speeds are lower and may occur near the operating speed. In order to analyze the problems related to the lateral bending of composite shafts, equivalent modulus theory is commonly used. The theory is based on Kirchoff's hypothesis for thin laminated beams. The equivalentmoduli are found us- ing classical laminate theory as shown by Bauchau [1981] and Singh and Gupta [1994a]. Bendingstretching, shear-normal and bending-twisting coupling terms are neglected. Brown and Rezin [1979] have compared the equivalent modulus method with an improved procedure called the "enforced symmetry method'. The latter approach includes the strain distribution as required by geometric symmetry. Thus the effect of bending-stretching coupling is included in an equivalent manner. Dos Reis et al. [1987a, b, and c] have used a finite element procedure in which beam elements were derived numerically from Donnel's shell theory, treating the tube as a two point boundary problem. In this way bending-stretching coupling effects were accounted for, and were shown to introduce different results. The effect of shear-normal coupling was also considered and it has been shown that these couplings induced changes in natural frequencies. Bert [1993], Bert and Kim [1995c] and Kim and Bert [1993] have incorporated the bending twisting coupling in composite shafts by including energy due to twisting deformation associated with bending. The results have been found to be in good agreement with experimental results for a rotor by Zinberg and Symmonds [1970].

When using thin and short shafts, two additional effects take place. Cross section deformation may occur during bending, thus affecting the flexural frequencies, and shell type modes may be excited during operation due to unsymmetric loading. Singh [1992] has shown that the difference between flexural mode frequencies calculated from the equivalent modulus beam theory and the shell theory is a measure of the amount of cross sectional deformation taking place. At low values of the length to radius ratio and the thickness to radius ratio of the composite cylinder, shell mode frequencies are close to flexural frequencies and would affect the flexural dynamic behavior. The interaction between the shell mode frequencies and flexural frequencies, and the applicability of equivalent modulus beam theory for accurate determination of natural frequencies of tubular shafts of different configurations (length/radius and thickness/ radius) have been discussed in detail by Singh and 
Gupta [1994a, 1994b]. Modal damping ratios are found to be more sensitive to parametric changes than the natural frequencies. The shell modes involving cross sectional deformation of nonrotating shafts have been experimentally analyzed by modal testing by Singh and Gupta [1993]. Tests showed the existence of coupling of higher flexural modes with shell modes. The mounting of a disc on the shaft resulted in suppression of some shell modes, reduction in flexural natural frequencies and increase in damping ratios of all modes. Bauchau and Chiang [1993] have also shown considerable difference in results between the anisotropic shallow-shell model and the beam model for anisotropic flexible beams.

In order to study the stress and strain fields in individual laminae and also to include the effects of the lamination scheme, longitudinal wall shear, a layerwise beam theory was derived from layerwise shell theory, by Singh and Gupta [1996b]. Results showed considerable improvement in prediction of the stress field and natural frequencies of shafts with an unsymmetric stacking sequence. Fish [1991] has adopted a quasi-three-dimensional approach to determine stress in a composite rotor. Comparison with results obtained by classical laminate theory shows significant differences in stress near structural discontinuities such as free edges and corners. Fish's analysis established the limitations of classical laminate theory when applied to thick walled shafts. Because of large $\mathrm{L} / \mathrm{R}$ ratios for practical shafts, transverse shear deformation TSD effect is neglected in some analyses. Zorzi and Giordano [1985] have obtained good correlations of first two critical speeds with experimental results. The analytical calculations for the test shafts were performed using a transfer matrix based procedure without shear deformation effects. However, it is generally recognized, Bank and Kao [1990], that neglect of transverse shear deformation TSD effects might give inaccurate results even for large $L / R$ ratio as compared to metallic shafts. This happens because of large E/G ratios, which are typical of composite materials. A number of recent works on composite shafts, for example by Bauchau [1981], Kraus [1988], and Singh and Gupta [1996a] have shown that equivalent modulus beam theory with shear deformation and rotary inertia effects included, gives sufficiently accurate results for critical speeds.

Another problem of paramount importance in composite shaft design has been that of optimization of the material and geometric parameters. The optimization objectives are somewhat different in aerospace applications as compared to automotive driveshaft design. In automotive applications, cost is one of the major driving factors. Thus, detailed cost-sensitivity analyses are performed in order to get a cost-optimal design. The solution lies in using hybrid composite shafts, as shown by Hoffmann [1989]. This provides the engineer with two important design variables to control, viz. the fiber winding angle and the mixing ratio of carbon and glass fibers. The additional variable of carbon:glass ratio greatly increases the range of design alternatives. Berg [1985] has discussed the cost sensitivity analysis of automobile driveshafts made from composite materials. Using elaborate optimization procedures, Belingardi et al. [1985] show that it is possible to produce composite driveshafts which are cost effective and give superior performance as compared to their metallic counterparts.

On the other hand, in aerospace applications, the primary criterion is performance related. Hence, typical objectives of optimization include minimization of weight, maximization and optimal placement of critical speeds and minimum dynamic response at operating speed. For shafts with potential usage in helicopters, elaborate algorithms have been developed for fine adjustments of the fiber winding angles and the stacking sequence. In one of the earliest studies carried by Zinberg and Symmonds [1970], a boron/ epoxy helicopter tail rotor driveshaft was optimized for minimum weight with critical speed, torsional buckling and strength as design criteria, which resulted in weight saving of $28 \%$.

In order to get optimum performance with minimum weight, Bauchau [1983] used tapered shafts in which different cross sections could contain different numbers of layers. Thus each layer was not completely wound throughout the full tube length. While meeting the torsional strength requirements, it was 
possible to obtain configurations which resulted in a 20-30\% increase of natural frequencies, as compared to constant thickness design, for the same weight. The dynamic stresses were also evaluated and it was observed that the optimized configurations resulted in $50-60 \%$ reduction of maximum dynamic stress. Lim and Darlow [1986] optimized a test composite shaft with a configuration of four layer groups $\left(0^{\circ}, \phi,-\phi\right.$, $90^{\circ}$ ). The design variables were the angle $\phi$ and the volume fractions of $0^{\circ}, 90^{\circ}$ and $\phi$ angle plies, and the radius and wall thickness of the tubular shaft. The optimization algorithm included the design requirements with respect to torsional vibrations, torsional buckling loads and lateral vibrations. It was found that super-critical operation using a single piece composite shaft could substantially increase the system weight reductions (upto $\approx 60 \%$ ). Even with sub-critical operations, system weight reductions as high as $40 \%$ were predicted. Similar optimization studies were also performed by Kraus and Darlow [1987], for a different configuration $(\alpha /-\alpha /-\alpha / \alpha / \gamma /-\gamma)$. The shafts were optimized using multi-criteria optimization and many constraints relating to strength and vibration considerations were applied. The objectives were, (i) minimization of shaft weight and (ii) optimal placement of critical speeds. The constraint placed on critical speeds was that no critical speeds should lie within $\pm 20 \%$ of the operating speed.

Darlow and Creonte [1995] have further optimized the shafts by allowing the fiber layup and thickness to vary along the shaft length. This was applied to a helicopter tail rotor and a synchronization shaft. Their results show that even a subcritical composite shaft with variable fiber layup and thickness could be much lighter than an aluminum shaft. Gupta et al. [1994] presented several design alternatives for an extremely flexible single span helicopter tail rotor with the constraints on shaft outer diameter, critical speed placement and buckling torque. Symmetric balanced lamination scheme with constant and variable ply thickness were used. The shaft wall thickness was constant. Gubran [1994] extended the above work by allowing variable wall thickness along the shaft axis. He determined the unbalance response and stresses in shafts with constant and variable wall thickness.

\section{DAMAGE TOLERANCE STUDIES}

The failure analysis of composite tubes is also a current research issue. Failure could be due to low velocity impact, [Figge et al., 1974], fatigue loadings, [Irretier, 1993], torsional buckling or bending buckling, [Bauchau et al., 1988].

During application of graphite/epoxy in automotive driveshafts, Figge et al. [1974] have shown the susceptibility of composite shafts to low velocity impacts. Efforts were directed towards methods of overcoming this problem. A low velocity impact in an automobile shaft is a very practical reality, because the shaft is exposed to the road surface. There are also the chances of low velocity impact occurring during manufacturing, handling and assembly. Figge et al. [1974] have addressed this problem for a helicopter driveshaft. Their design used a hybrid shaft, constructed with uni-directional boron/epoxy composite sheathed with inner and outer metallic tubes. The new arrangement was experimentally shown to be better. A major part of this problem is being tackled by material scientists through the development of tough resin systems. This work continues. A recent study of low velocity impact damage in composite helicopter driveshafts has been conducted by Minguet [1993]. Three resin systems, viz. epoxy, toughened epoxy and thermoplastic PEEK were studied and compared for their damage resistance to low velocity impact. It was noted that, while toughened epoxy showed greatest resistance to low velocity impact, the thermoplastic shaft had the highest residual strength after impact. Ayers and Ochoa [1993] have tested composite shafts with and without ballistic damage, under static as well as dynamic loads, to obtain their material, mechanical and vibrational characteristics.

Another important failure mode in composite material components is by delamination propagation. Extensive studies have been conducted on delamination for different structures. A recent work by Chandramouli et al. [1994] addressed the problem of delamination propagation in a rotating carbon/epoxy composite shaft. If the shaft whirl orbit is non-circular, the shaft experiences cyclic loading. The delami- 
nation propagation rate is related to the revolutions of the shaft, and by imposing a fatigue crack growth model, the relevant material constants are determined. Irretier [1993] has studied the delaminationgrowth in a composite shaft using a modal analysis technique. The shaft was loaded in a pulsating testing machine and, after a number of loading cycles, delamination growth was studied. The bifurcation of frequency at the site of delamination was found to be a more reliable method of predicting delamination than changes in modal damping values.

Buckling loads in both the bending and torsion modes have been experimentally determined by Bauchau [1981]. Experiments showed that bending of thin walled tubes is a non-linear phenomenon, because the cross section is deformed. Thus, conventional beam theory can not be applied for estimating strength and failure in bending. The torsional buckling loads were also obtained from an analytical formulation. The analytical predictions correlate well with experimental values. Bauchau et al. [1988] have shown that torsional strength is greatly affected by the stacking sequence. Secondly, experiments proved that failure is governed more by the stiffness criterion than by the strength criterion. The effect of delamination, and circular holes on the circumference, was also investigated. Recently, Bert and Kim [1995] have presented theoretical analysis for determining buckling torque of an arbitrarily laminated circular cylindrical hollow composite shaft using various thin shell theories. The effect of off-axis stiffnesses and bending moment on buckling torque was considered.

One of the important aspects of tubular shafts has been the accurate measurement of the material properties. Pagano and Whitney [1970] and Whitney [1971] published important works related to characterization of tubular specimens. Spencer [1987] used axial and torsional vibration measurement for evaluation of Young's modulus E, and torsional modulus G. A number of experiments were conducted to validate the method. The marginal change in natural frequency because of damping has been accounted for in calculations of stiffness and moduli. Bauchau's [1981] work also involved the determination of $\mathrm{E}$ and $\mathrm{G}$ values. The determination of moduli in complex form i.e. including damping loss factor has been performed by Andriulli [1989] using modal analysis techniques.

\section{ROTORDYNAMIC STUDIES}

Analytical and experimental studies on rotordynamic aspects of composite shaft behaviour are few, and are relatively recent. Table 1 summarizes the various configurations used for composite shaft rotordynamic studies. It may be noticed, from the table that the shaft geometric parameters (Length/radius and thickness/radius ratios) vary over a wide range, which might explain some of the differing experiences of various authors.

Zinberg and Symmonds [1970] described a boron/ epoxy composite tail rotor driveshaft for a helicopter. The critical speeds were determined using equivalent modulus beam theory, assuming the shaft to be a thin walled circular tube simply supported at the ends. Shear deformation was not taken into account. The shaft critical speed was determined by extrapolation of the unbalance response curve which was obtained in the sub-critical region.

Bauchau [1981] performed a series of important investigations on composite shafts. The emphasis of the study was on determination of stiffness, strength characteristics and stresses under unbalance condition. The shafts were run in torsion using a water brake at one end. The strains were measured using strain gages. The bending stresses due to unbalance excitation, determined experimentally, were much larger than those calculated using beam theory and the difference was explained as due to non-linear effects. For calculation of the lateral bending critical speed, a finite element formulation based on Timoshenko beam theory was used. However, the shafts were operated in the sub-critical region, and typical rotordynamic phenomena were not studied.

Zorzi and Giordano [1985] conducted rotordynamic experiments on an aluminum shaft and two composite shafts. The aluminum shaft was tested for baseline comparison purposes, and in order to calcu- 
TABLE 1 Configurations used for tubular composite shaft rotordynamic analysis

\begin{tabular}{|c|c|c|c|}
\hline Author & Shaft Dimensions & Operation (Max. Speed) & Material [Fiber Lay-up] \\
\hline Zinberg and Symmonds [1970] & $\begin{aligned} \mathrm{R} & =12.7 \mathrm{~cm} \\
\mathrm{~L} / \mathrm{R} & =20.6 \\
\mathrm{t} / \mathrm{R} & =0.103\end{aligned}$ & $\begin{array}{l}\text { Sub-critical } \\
(<5500 \mathrm{RPM})\end{array}$ & $\begin{array}{l}\text { boron/epoxy } \\
{\left[90^{\circ}, 45^{\circ},-45^{\circ}, 0_{6}^{\circ}, 90^{\circ}\right]}\end{array}$ \\
\hline Bauchau [1981] & $\begin{array}{c}\mathrm{R}=4.48 \mathrm{~cm} \\
\mathrm{~L} / \mathrm{R}=32.3 \\
\mathrm{t} / \mathrm{R}=.07-.14 \\
\text { (Tapered Shafts) }\end{array}$ & Sub-critical & $\begin{array}{l}\text { graphite/epoxy } \\
{\left[0^{\circ}{ }_{2}, 45^{\circ}, 0^{\circ}{ }_{2},-45^{\circ},\right.} \\
\left.0^{\circ}{ }_{2}, 45^{\circ},-45^{\circ}\right]\end{array}$ \\
\hline Zorzi and Giordano [1985] & $\begin{aligned} \mathrm{R} & =1.59 \mathrm{~cm} \\
\mathrm{~L} / \mathrm{R} & =68.6 \\
\mathrm{t} / \mathrm{R} & =0.19\end{aligned}$ & $\begin{array}{l}\text { Super-Critical } \\
9500 \text { RPM } \\
\text { (with disks) }\end{array}$ & $\begin{array}{l}\text { Hybrid of } \\
\text { glass/epoxy and } \\
\text { graphite/epoxy } \\
{\left[ \pm 45^{\circ}(\mathrm{HS}), \pm 10^{\circ}\right.} \\
(\mathrm{HM}), 90^{\circ} \text { (E-glass)] }\end{array}$ \\
\hline Kraus [1988] & $\begin{aligned} \mathrm{R} & =1.2 \mathrm{~cm} \\
\mathrm{~L} / \mathrm{R} & =203 \\
\mathrm{t} / \mathrm{R} & =0.074\end{aligned}$ & $\begin{array}{l}\text { Super-Critical } \\
3800 \text { RPM }\end{array}$ & $\begin{array}{l}\text { graphite/epoxy } \\
{\left[ \pm 40^{\circ}, \pm 5^{\circ}\right]}\end{array}$ \\
\hline Singh and Gupta [1996a] & $\begin{aligned} \mathrm{R} & =5.2 \mathrm{~cm} \\
\mathrm{~L} / \mathrm{R} & =21.7 \\
\mathrm{t} / \mathrm{R} & =0.096\end{aligned}$ & $\begin{array}{l}\text { Super-Critical } \\
4000 \text { RPM }\end{array}$ & $\begin{array}{l}\text { graphite/epoxy } \\
{\left[ \pm 45^{\circ}(\mathrm{I}, \mathrm{S} 45 \mathrm{M})\right.} \\
\left. \pm 60^{\circ}(\mathrm{II}, \mathrm{S} 60 \mathrm{M})\right]\end{array}$ \\
\hline
\end{tabular}

$\mathrm{R}=$ Mean Radius; $\mathrm{L}=$ Length; $\mathrm{t}=$ Wall Thickness.

late the critical speed payoffs. The composite shafts were filament wound and consisted of three different layers of graphite/epoxy and glass/epoxy. Two metallic stub shafts, one at each end, were used for mounting of the rotor in rolling element bearings. Experimental testing was carried out on all three shafts, with and without lumped mass disks. Some important observations were made during the experimental studies. The super-synchronous component corresponding to first critical speed became significant when the shaft speed reached $1 / 2$ or $1 / 3$ of the first critical speed. It was shown that, although the shafts were not of optimized design, a substantial payoff in terms of critical speed was achievable. From the balancing point of view, the shafts were shown to have increased sensitivity to unbalance near the critical speed. This was determined from the large values of influence coefficients near the critical speeds and a very small value of the final correction masses.

Dos Reis et al. [1987a, b, and c] published analytical investigations on thin-walled layered composite cylindrical tubes. In part III of the series of publications, the beam element was extended to formulate the problem of a rotor supported on general eightcoefficient bearings. Results were obtained for shaft configuration of Zinberg and Symmonds. The authors have shown that bending-stretching coupling and shear-normal coupling effects change with stacking sequence, and alter the frequency values. Gupta and Singh [1996] studied the effect of shear-normal coupling on rotor natural frequencies and modal damping. Kim and Bert [1993] have formulated the problem of determination of critical speeds of a composite shaft including the effects of bending-twisting coupling. The shaft was modelled as a Bresse-Timoshenko beam. The shaft gyroscopics have also been included. The results compare well with Zinberg's rotor [1970]. In another study, Bert and Kim [1995a] have analysed the dynamic instability of a composite drive shaft subjected to fluctuating torque and/or rotational speed by using various thin shell theories. The rotational effects include centrifugal and Coriolis forces. Dynamic instability regions for a long span simply supported shaft are presented.

Lim and Darlow [1986] and Hetherington et al. [1990] conducted a series of studies on composite shafts. The optimized shafts were manufactured using a braiding technique and were tested for rotordynamic performance. The shafts were tested under no load condition. A unified balancing approach was applied to balance the shaft up to the second critical speed. An aluminum shaft was tested for comparison 
purposes. The shafts, however, had an initial bend. Just above the first critical speed, a beat motion with constituent frequencies as synchronous speed and shaft natural frequency was observed. An external damper was needed to pass the critical speed. Frederick and Darlow [1991], also, achieved the supercritical operation of a graphite/epoxy composite shaft, above the second critical speed, in the presence of torsional loading.

Additional recent work on composite shafts dealing with both the theoretical and experimental aspects, was reported by Singh [1992], Gupta and Singh [1996] and Singh and Gupta [1994c, 1996a and b]. Rotordynamic formulation based on equivalent modulus beam theory was developed for a composite rotor with a number of lumped masses, and supported on general eight coefficient bearings. A layerwise beam theory was derived by Singh and Gupta [1996b] from an available shell theory, with a layerwise displacement field, and was then extended to solve a general composite rotordynamic problem. The conventional rotor dynamic parameters viz. critical speeds, natural frequencies, damping factors, unbalance response and threshold of stability were analyzed in detail and results from the formulations based on the two theories, namely, the equivalent modulus beam theory and layerwise beam theory were compared [Singh and Gupta, 1994c]. The experimental rotordynamic studies carried by Singh and Gupta [1995, 1996a] were conducted on two filament wound carbon/epoxy shafts with constant winding angles $\left( \pm 45^{\circ}\right.$ and $\pm 60^{\circ}$ ). Progressive balancing had to be carried out to enable the shaft to traverse through the first critical speed. Inspite of the very different shaft configurations used (Table 1), the authors' experience was similar to that of Zorzi and Giordano's [1985] in terms of high rotor sensitivity to unbalance, absence of any instability at resonance and excitation of resonance by supersynchronous components at rotor speeds equal to one half and one third of rotor critical speed. The presence of supersynchronous components was more pronounced in the shaft having $60^{\circ}$ fiber angle (compared to $45^{\circ}$ fiber angle) and was suppressed when the balance condition of the rotor improved. The most likely cause appears to be material non-linearity derived from the matrix. Damping measurements from rap test on rotating and non rotating composite shafts are also reported by Gupta and Singh [1996]. Some practical aspects such as effect of shaft disc angular misalignment, interaction between shaft bow, which is common in composite shafts and rotor unbalance, and an unsuccessful operation of a composite rotor with an external damper were discussed and reported by Singh and Gupta [1995]. The Bode and cascade plots were generated and orbital analysis at various operating speeds was performed. The experimental critical speeds showed good correlation with the theoretical prediction.

\section{CONCLUDING REMARKS}

The application of composite shafts has come a long way from early low speed automotive driveshafts to helicopter tail rotors operating above the second critical speed. With operation at supercritical speeds, a substantial amount of payoffs and net system weight reductions are possible. At the same time, the rotordynamic aspects assume more importance, and detailed analysis is required. There are some technological problems associated with implementation, such as joints with bearings, affixing of lumped masses, couplings, provision of external damping etc. The solutions proposed are just adequate, but require substantial refinements. One of the recent alternatives being suggested is to have integral couplings and masses, which are added during the shaft winding stage itself, as suggested by Faust et al. [1988] and Margasahayam and Faust [1988], and non-circular end cross section, Gross and Goree [1993]. Secondly, the problem of low velocity impact damage has been a serious limitation of composite shafts. One of the solutions, by which these problems could be overcome to a large extent, is the use of metal matrix composite shafts. These materials would be particularly suitable when using composite shafts for turbomachinery applications, where high temperatures are encountered. Issues in development of an all-compos- 
ite aero-gas turbine engine rotor were addressed in some detail by Gupta [1994]. Use of smart composites as shown by Baz [1993], with potential application to active control of rotor vibrations/instabilities, throws up interesting possibilities for the future, but research activity has yet to pick up momentum in this direction.

\section{Acknowledgements}

Support provided by Aeronautics R \& D Board, Government of India, is gratefully acknowledged.

\section{References}

[1] Andriulli, J. B. (1989). Measured Damping and Modulus of Composite Cylinders, Proceedings Damping '89, pp. BCC1-BCC-26.

[2] Ayers, T. R., and Ochoa, O. O. (1993). Effects of Ballistic Damage on Dynamics of Composite Drive Shaft, Proceedings of ASME 16th Annual Energy-Sources Technology Conference \& Exhibition, Houston, PD Vol. 53, pp. 24j247.

[3] Bank, L. C. and Kao, C. H. (1990). Dynamic Response of Thin Walled Composite Material Timoshenko Beams, Journal of Energy Resources Technology, Vol. 112, pp. 149-154.

[4] Bauchau, O. A. (1981). Design, Manufacturing and Testing of High Speed Rotating graphite/epoxy Shafts, Doctorate Thesis, Department of Aeronautics and Astronautics, MIT.

[5] Bauchau, O. A. (1983). Optimal Design of High Speed Rotating graphite/epoxy Shafts, Journal of Composite Materials, Vol. 17, pp. 170-181.

[6] Bauchau, O. A. and Chiang, W. (1993). Dynamic Analysis of Rotor Flexbeams based on Nonlinear Anisotropic Shell Models, Journal of American Helicopter Society, Vol. 38, no. 1, pp. 55-61

[7] Bauchau, O. A., Krafchack, T. M. and Hayes, J. F. (1988) Torsional Buckling Analysis and Damage Tolerance of graphite/epoxy Shafts, Journal of Composite Materials, Vol. 22, pp. 258-270.

[8] Baz, A. and Chen, T. (1993). Torsional stiffness of NITINOL-Reinforced Composite Drive Shafts, Composite Engineerings, Vol. 3, no. 3, pp. 1119-1130.

[9] Belingardi, G., Calderale, P. M. and Rosetto, M. (1990). Design of Composite Material Drive Shafts for Vehicular Applications, International Journal of Vehicle Design, Vol. 11, no. 6, pp. 553-563.

[10] Belingardi, G., Genta, G. and Campagna, P. (1985). Hybrid Composite Technology for Automotive Drive Shaft: a Computer aided Optimization, Proceedings of International Symposium on Automotive Technology and Automation (ISATA 85), Graz Austria, Vol. 2, pp. 511-524.

[11] Berg, K. R. (1985). Cost Sensitivity in Composite Driveshafts, Advanced Composites-Conference Proceedings, Dearborn, Michigan, USA, pp. 59-68.
[12] Berg, K. R. (1989). Composite Driveshafts in Cooling Towers, Journal of Cooling Tower Institute, Vol. 10, no. 1, pp. 36-37, 40-43.

[13] Bert, C. W. (1993). The Effect of Bending-Twisting Coupling on the Critical Speed of a Driveshaft", Proceedings 6th Japan-US Conference on Composite Materials, Orlando, FL, Techonomic, Lancaster, PA, pp. 29-36.

[14] Bert, C. W. and Kim, C. D., 1995a. Dynamic Instability of Composite-Material Drive Shaft Subjected to Fluctuating Torque and/or Rotational Speed", Dynamics and Stability of Systems, Vol. 10, no. 2, pp. 125-147.

[15] Bert, C. W. and Kim, Chun-Do (1995b). Analysis of Buckling of Hollow Laminate Composites Drive Shafts, Composite Science and Technology, Vol. 53, no. 3, pp. 343-351.

[16] Bert, C. W. and Kim, C. D. (1995c). Whirling of Composite Material Driveshafts including Bending-Twisting Coupling and Transverse Shear Deformation, ASME Journal of Vibration and Acoustics Vol. 117, no. 1, pp. 17-21.

[17] Bielefield, M. (1994). Fabrication of Braided RTM Driveshaft Tubes for the RAH-60 Comanche, Proceedings of the 50th Annual Forum of American Helicopter Society, Washington, DC, USA, Vol. 2, pp. 1001-1015.

[18] Brown, T. S. and Rezin, D. B. (1979). Hybrid Composite Drive Shaft Design Considerations, ASME Special Publication, Modern Developments in Composite Materials and Structures, Winter Annual Meeting, pp. 173-187.

[19] Chandramouli, G., Gupta, K. and Pandey, R. K. (1994). Delamination Propagation in Rotating carbon-epoxy Composite Shafts, Engineering Fracture Mechanics, Vol. 49, no. 1, pp. 121-132.

[20] Cox, J. (1994). Carbon Fiber Shafts., Papermaker, Vol. 57, no. 10, p. 25.

[21] Darlow, M. S. and Creonte, J. (1995). Optimal Design of Composite Helicopter Power Transmission Shafts with Axially Varying Fiber Layup, Journal of American Helicopter Society, Vol. 40, no. 2, pp. 50-56.

[22] Dos Reis Henrique, L. M. and Goldman, R. B. (1987a). Thin Walled Laminated Composite Cylindrical Tubes-Part I-Boundary Value Problems, ASTM Journal of Composites Technology and Research, Vol. 9, no. 2, pp. 47-52.

[23] Dos Reis Henrique, L. M. and Goldman, R. B. (1987b). Thin Walled Laminated Composite Cylindrical Tubes-Part II-Bending Analysis, ASTM Journal of Composites Technology and Research, Vol. 9, no. 2, pp. 53-57.

[24] Dos Reis Henrique, L. M., Goldman, R. B. and Verstrate, P. H. (1987c). Thin Walled Laminated Composite Cylindrical Tubes-Part III, Critical Speed Analysis, ASTM Journal of Composites Technology and Research, Vol. 9, no. 2, pp. 58-62.

[25] Faust, H. et al. (1988). Development of an Integral Composite Drive Shaft and Coupling, AHS National Technical Specialists Meeting on Advanced Rotorcraft Structures, Williamsburg VA.

[26] Figge I. E., et al. (1974). Low Weight Impact Resistant Helicopter Driveshafts, Composite materials: Testing and Design (Third Conference) ASTM STP 546, American Society for Testing and Materials, pp. 651-662.

[27] Fish, J. C. (1991). Stress Analysis of Composite Rotor Systems, Proceedings of Annual Forum of American Helicopter Society, Alexandria, Vol. 1, pp. 615-627.

[28] Frederick, J. R. and Darlow, M. S. (1991). Operation of Torsionally Loaded Composite Shaft above two flexural critical speeds, 13th Biennial Conference on Mechanical Vibration and Noise, presented at 1991 ASME Design Technical Conference, Miami, FL, USA, Vol. 36, pp. 247-255.

[29] Fromknecht, T. G. (1992). Composite Technology in Cou- 
plings and Shaftings for Power Transmission, Proceedings ASME International Power Transmission and Gearing Conference, DE, Vol. 43, pt 2, pp. 575-581.

[30] Garguilo, D. J. (1986). Design and Development of a Power Takeoff Shaft, Journal of Aircraft, Vol. 23, no. 12. pp. 876880.

[31] Golding, J. H. (1982). Fiber Reinforced Plastics in the Manufacture of Automotive Propeller Shafts, Proceedings Drive and Plastics Conference. (Plastics \& Rubber Institute, London), p. 3.1-3.15.

[32] Gross, R. S. and Goree, J. G. (1993). Expérimental and Analytical Investigations of Composite Drive Shafts with Noncircular end Cross Sections, Journal of Composite Materials, Vol. 27, no. 7, pp. 702-720.

[33] Gubran, H. B. H. (1994). Optimum Design of a Helicopter Tail Rotor Made of Composite Material.", Masters Thesis, Mechanical Engineering Department, IIT, Delhi, India.

[34] Gupta, K. (1994). Some Issues on Design and Development of an all Composite Aero Gas Turbine Engine Rotor, Proceedings National Symposium on Developments in Advanced Composites and Structures, DRDL, Hyderabad, India, pp. 110-117.

[35] Gupta, K. and Singh, S. P. (1996). Dynamics of Composite Rotors, Proceedings of Indo-US symposium on Emerging Trends in Vibration and Noise Engineering, New Delhi, India, pp. $59-70$

[36] Gupta, K., Kadre, S., and Sigh, S. P. (1994). Design Alternatives for a Fiber Reinforced Composite Helicopter Tail Drive Rotor, Proceedings of National Symposium on Developments in Advanced Composites and Structures, DRDL, Hyderabad, India, pp. 17-24.

[37] Hetherington, P. L., Kraus, R. F. and Darlow, M. S. (1990). Demonstration of a Super Critical Composite Helicopter Power Transmission Shaft, Journal of American Helicopter Society, Vol. 35, no. 1, pp. 23-28.

[38] Hoffmann, W. (1989). Fiber Composite in the Driveline, Plastics and Rubber International, Vol. 14, no. 5, pp. 46-49.

[39] Hoffmann, W. Schafferus, T. and Rouillot, M. (1994). Second Generation of Composite Propshafts, ATZ Automobiltechnische-Zeitschrift, Vol. 96, no. 10, pp 612-617.

[40] Irretier, H. (1993). Crack Detection in Composite Driving Shafts by Experimental Modal Analysis, DE-Vol. 64, Vibration, Shock, Damage, and Identification of Mechanical Systems, ASME, pp. 23-38.

[41] Kim, C. D. and Bert, C. W. (1993). Critical Speed Analysis of Laminated Composite Driveshafts, Composites Engineering, Vol. 3, nos. 7-8, pp. 633-643.

[42] Kliger, H. S. and Yates, D. N. (1980). Design and Material Implications of Composite Drive Shafts, Advances in Composite Materials, ICCM3, Edited by A. R. Bunsell, Oxford, Pergamon Press, pp. 1335-1346.

[43] Kraus, R. F. (1988). Design and Experimental Studies on Supercritical Composite Power Transmission Shafting, Doctorate Thesis, Department of Mechanical Engineering, Aeronautical Engineering and Mechanics, RPI.

[44] Kraus, R. F. and Darlow, M. S. (1987). Design and Experimental Studies of Composite Power Transmission Shafting, American Helicopter Society 43rd Annual Forum, St. Louis, Mo., Vol. 2, pp. 733-738.

[45] Lim, J. W. and Darlow, M. S. (1986). Optimal Sizing of Composite Power Transmission Shafting, Journal of American Helicopter Society, Vol. 31, no. 1, pp. 75-83.

[46] Linsenmann, D. R. (1978). Hybridization for Cost Effective Design, ASME Special Publication, Composite Materials in The Automobile Industry, Winter Annual Meeting, pp. 4350 .
[47] Margasahayam, R. N. and Faust, H. S. (1988). Composite Drive Shaft Coupling for Future Rotorcraft: A 3D Finite Element Analysis, ASME Design Automation Conference, Design Engineering Div, DE. Vol. 14, pp. 337-343.

[48] Minguet, P. J. A. (1993). Damage Tolerance Evaluation of New Manufacturing Techniques for Composite Helicopter Drive Shafts, AIAA-93-1400-CP, pp. 867-876.

[49] Pagano N. J. and Whitney, J. M. (1970). Geometric Design of Composite Cylindrical Characterization Specimens, Journal of Composite Materials, Vol. 4, pp. 340-353.

[50] Raghava, R. S. and Hammond, R. S. (1984). Development of a Filament Wound Composite Shaft for an Aircraft Generator, Technical Sessions of the 39th Annual ConferenceReinforced Plastics/Composites Institute, Newyork, pp. $1-24$.

[51] Singh, S. P. (1992). Some Studies on Dynamics of Composite Shafts, Ph.D thesis, Mechanical Engineering Department, IIT, Delhi, India

[52] Singh, S. P. and Gupta, K. (1993). Modal Testing of Tubular Composite Shafts, Proceedings of the 11th International Modal Analysis Conference, Florida, USA, pp. 733-739.

[53] Singh, S. P. and Gupta, K. (1994a). Free Damped Flexural Vibration Analysis of Composite Cylindrical Tubes using Beam and Shell Theories, Journal of Sound and Vibration, Vol. 172, no. 2, pp. 171-190.

[54] Singh, S. P. and Gupta, K. (1994b). Damped Free Vibrations of Layered Composite Cylindrical Shells, Journal of Sound and Vibration, Vol. 172, no. 2, pp. 191-209.

[55] Singh, S. P. and Gupta, K. (1994c). Dynamic Analysis of Composite Rotors, 5th International Symposium on Rotating Machinery (ISROMAC-5), also International Journal of Rotating Machinery, Vol. 2, no. 3, pp. 179-186, 1996.

[56] Singh, S. P. and Gupta, K. (1995). Experimental Studies on Composite Shafts, Proceedings of the International Conference on Advances in Mechanical Engineering, Bangalore, India, pp. 1205-1221.

[57] Singh, S. P. and Gupta, K. (1996a). Rotordynamic Experiments on Composite Shafts. To appear in ASTM Journal of Composite Technology and Research.

[58] Singh, S. P. and Gupta, K. (1996b). Composite Shaft Rotordynamic Analysis using a Layerwise Theory, Journal of Sound and Vibration, Vol. 191, no. 5, pp 739-756.

[59] Spencer, A. (1987). Young's Modulus and Shear Modulus of a Composite Shaft from Resonance Measurements, Composites Science and Technology, Vol. 28, no. 3, pp. 173191.

[60] Spencer, B. E. (1989). Advances in Power Transmission using Filament Wound Composites, 34th International SAMPE Symposium and Exhibition, Vol. 34, Tomorrow's Materials: Today, pp. 1109-1117.

[61] Spencer, B. and McGee, J. (1985). Design Methodology for a Composite Driveshaft, Advanced Composites, Conference Proceedings, Dearborn, Michigan, pp. 69-82.

[62] Whitney, J. M. (1971). On the use of Shell Theory for Determining Stresses in Composite Cylinders, Journal of Composite Materials, Vol. 5, pp. 340-353.

[63] Wilhelmi, G. F. Appleman, W. M. and Loo, F. T. C. (1986). Composite Shafting for Naval Propulsion Systems, Naval Engineers Journal, Vol. 98, no. 4, pp. 129-136.

[64] Worgan, G. and Smith, D. (1978). Carbon Fiber Driveshaft, US Patent no. 4089190.

[65] Yates, D. and Rezin, D. (1979). Carbon Fiber Reinforced Composite Driveshafts, US Patent no. 4171626.

[66] Zinberg, H. and Symmonds, M. F. (1970). The Development of an Advanced Composite Tail Rotor Driveshaft, Pre- 
sented at 26th Annual National Forum of American Helicopter Society, Washington, DC.

[67] Zorzi, E. S. and Giordano, J. C. (1985). Composite Shaft
Rotor Dynamic Evaluation, Presented at ASME Design Engineering Conference on Mechanical Vibrations and Noise, Sept. 1985, ASME paper no. 85-DET-114, pp. 1-8. 


\section{ait \\ ENERGY MATERIALS}

M A N E Y publishing

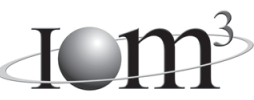

\section{Materials Science \& Engineering for Energy Systems}

Maney Publishing on behalf of the Institute of Materials, Minerals and Mining

The Institute of Materials, Minerals \& Mining

Economic and environmental factors are creating ever greater pressures for the efficient generation, transmission and use of energy. Materials developments are crucial to progress in all these areas: to innovation in design; to extending lifetime and maintenance intervals; and to successful operation in more demanding environments. Drawing together the broad community with interests in these areas, Energy Materials addresses materials needs in future energy generation, transmission, utilisation, conservation and storage. The journal covers thermal generation and gas turbines; renewable power (wind, wave, tidal, hydro, solar and geothermal); fuel cells (low and high temperature); materials issues relevant to biomass and biotechnology; nuclear power generation (fission and fusion); hydrogen generation and storage in the context of the 'hydrogen economy'; and the transmission and storage of the energy produced.

As well as publishing high-quality peer-reviewed research, Energy Materials promotes discussion of issues common to all sectors, through commissioned reviews and commentaries. The journal includes coverage of energy economics and policy, and broader social issues, since the political and legislative context influence research and investment decisions.

\section{CALL FOR PAPERS}

Contributions to the journal should be submitted online at http://ema.edmgr.com

To view the Notes for Contributors please visit: www.maney.co.uk/journals/notes/ema

Upon publication in 2006, this journal will be available via the Ingenta Connect journals service. To view free sample content online visit: www.ingentaconnect.com/content/maney

For further information please contact:

Maney Publishing UK

Tel: +44 (0)113 2497481 Fax: +44 (0)1132486983 Email: subscriptions@maney.co.uk

or

Maney Publishing North America

Tel (toll free): 8662975154 Fax: 6173546875 Email: maney@maneyusa.com

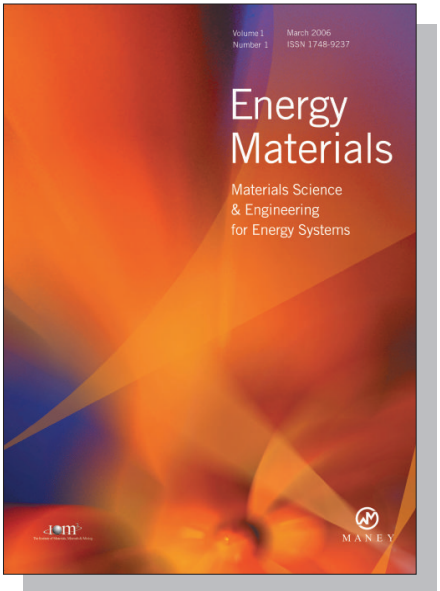

EDITORS

Dr Fujio Abe

NIMS, Japan

Dr John Hald, IPL-MPT, Technical University of Denmark, Denmark

Dr R Viswanathan, EPRI, USA

\section{SUBSCRIPTION INFORMATION}

Volume 1 (2006), 4 issues per year

Print ISSN: 1748-9237 Online ISSN: 1748-9245

Individual rate: $£ 76.00 / U S \$ 141.00$

Institutional rate: $£ 235.00 /$ US $\$ 435.00$

Online-only institutional rate: $£ 199.00 / U S \$ 367.00$

For special $\mathrm{IOM}^{3}$ member rates please email

subscriptions@maney.co.uk

\section{For further information or to subscribe online please visit www.maney.co.uk}



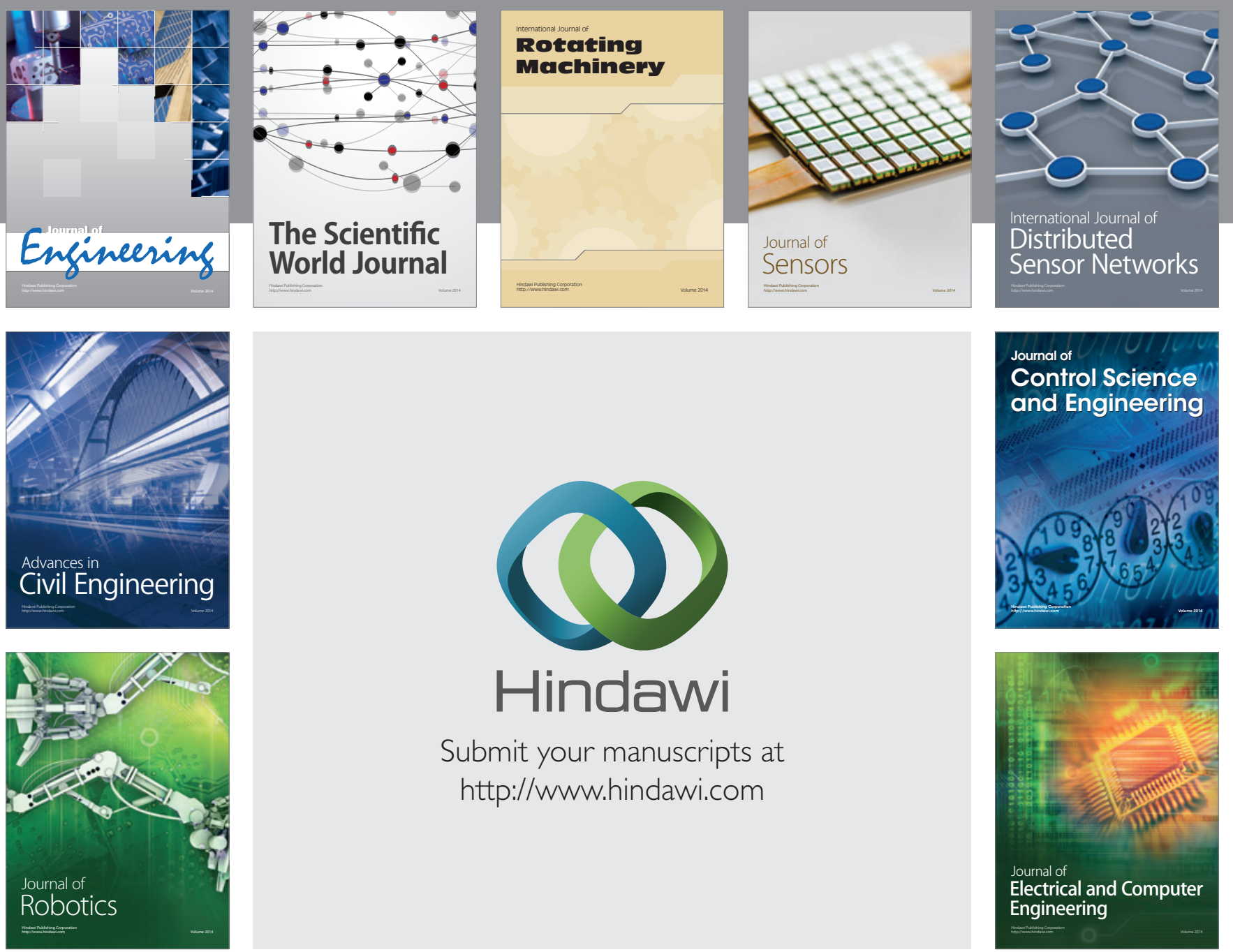

Submit your manuscripts at

http://www.hindawi.com
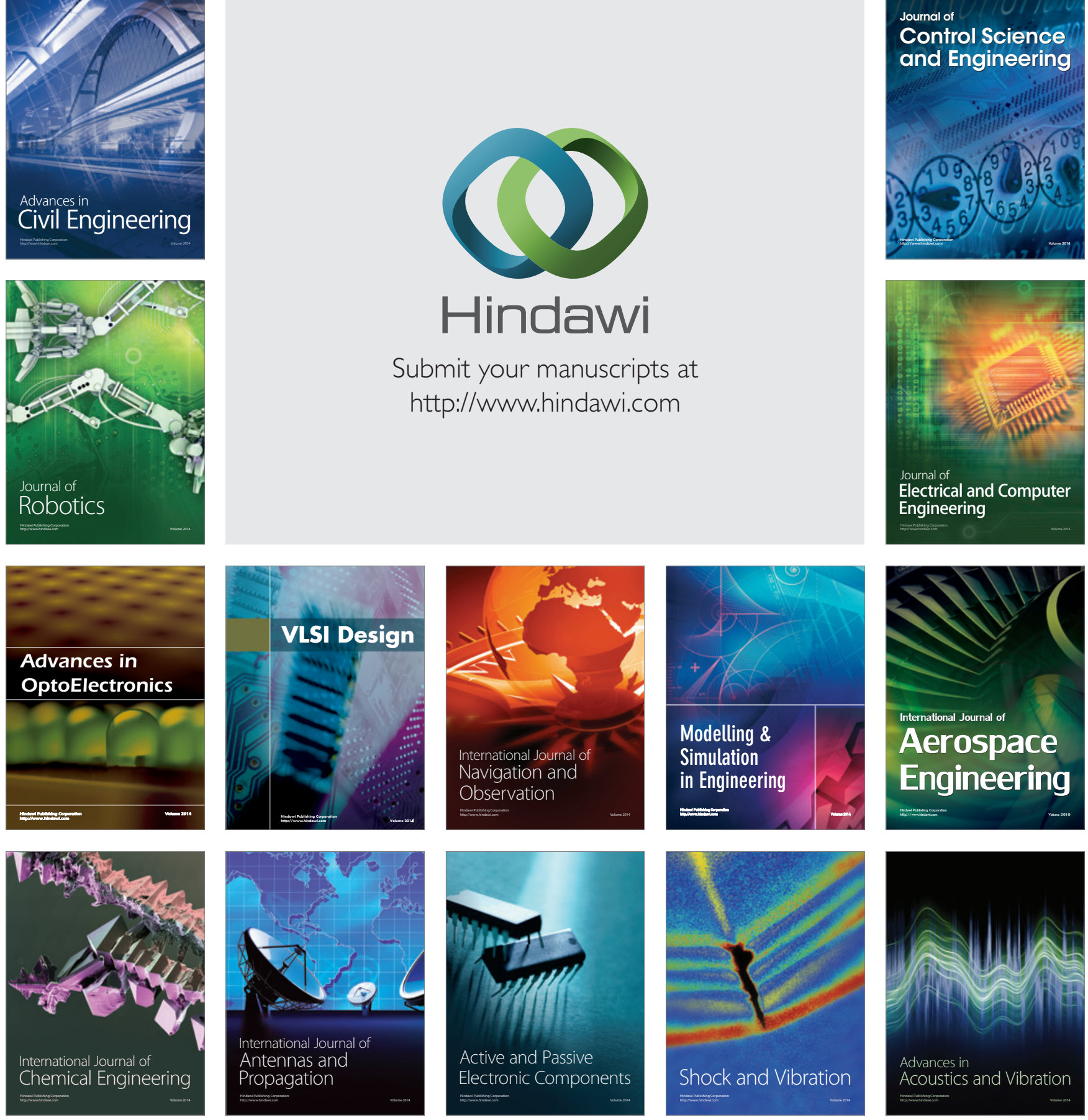